IZA DP No. 7428

A Model of Worker Investment in Safety and Its Effects on Accidents and Wages

José R. Guardado

Nicolas R. Ziebarth

May 2013 


\title{
A Model of Worker Investment in Safety and Its Effects on Accidents and Wages
}

\author{
José R. Guardado \\ American Medical Association \\ Nicolas R. Ziebarth \\ Cornell University, PAM, \\ IZA and DIW Berlin
}
Discussion Paper No. 7428
May 2013

\author{
IZA \\ P.O. Box 7240 \\ 53072 Bonn \\ Germany \\ Phone: +49-228-3894-0 \\ Fax: +49-228-3894-180 \\ E-mail: iza@iza.org
}

Any opinions expressed here are those of the author(s) and not those of IZA. Research published in this series may include views on policy, but the institute itself takes no institutional policy positions. The IZA research network is committed to the IZA Guiding Principles of Research Integrity.

The Institute for the Study of Labor (IZA) in Bonn is a local and virtual international research center and a place of communication between science, politics and business. IZA is an independent nonprofit organization supported by Deutsche Post Foundation. The center is associated with the University of Bonn and offers a stimulating research environment through its international network, workshops and conferences, data service, project support, research visits and doctoral program. IZA engages in (i) original and internationally competitive research in all fields of labor economics, (ii) development of policy concepts, and (iii) dissemination of research results and concepts to the interested public.

IZA Discussion Papers often represent preliminary work and are circulated to encourage discussion. Citation of such a paper should account for its provisional character. A revised version may be available directly from the author. 


\section{ABSTRACT \\ A Model of Worker Investment in Safety and Its Effects on Accidents and Wages}

In this paper, we develop a theoretical model of worker investment in safety. Standard theory assumes that injury risk is exogenous. It predicts that riskier jobs are associated with higher wages. In contrast, in our model, workers make individual safety investments that reduce the risk of injury. This results in a negative association between individual injury risk and wages. We test the model's predictions using obesity as a proxy for worker disinvestments in human capital and safety. In line with our model predictions, we find a significant positive compensating wage differential (CWD) for nonfatal risk at the occupational level. At the same time, however, there exists an underlying significant negative association between individual accident risk and wages, but only in high risk occupations. The latter relationship may downward bias or mask CWD estimates.

JEL Classification: I10, I12, J24, J31, J62, J71

Keywords: worker investment, safety, nonfatal risk, compensating wage differential, obesity

Corresponding author:

Nicolas Ziebarth

Cornell University

Policy Analysis and Management

106 MVR

Ithaca, NY 14850

USA

E-mail:nrz2@cornell.edu

\footnotetext{
* We want to send a strong thanks and acknowledgement to Bob Kaestner for all his encouragement and for the many discussions and comments he contributed. We also thank John Cawley, Barry Chiswick, Michael Grossman, Lorens Helmchen, Evelyn Lehrer, Magnus Lofstrom, Rodrigo Soares, Erdal Tekin, Nathan Tefft, and seminar participants at the University of Illinois at Chicago and at the 2013 IZA Annual Meeting on the Economics of Risky Behavior (AMERB) for their helpful suggestions. In particular, we thank Corrado Giulietti for an excellent discussion of the paper. We also would like to thank Lauren Jones for outstanding research assistance. The views in this paper are those of the authors and should not be construed to represent the views of the American Medical Association or Cornell University. All errors are our own.
} 


\section{Introduction}

Since Adam Smith, economists have theorized that workers must be compensated for unpleasant working conditions, where one of the most important characteristics is workplace safety. Economists are interested in the relationship between on-the-job-risk and wages because it informs us about the way the labor market works. Policymakers care about it because it is used as an estimate of how much people value workplace conditions and their health.

Standard economic theory assumes that firms face a tradeoff between compensating workers for an increased risk of accidents or reducing this risk by investing in workplace safety (and paying lower wages). Thus, firms invest in safety until marginal benefits - a lower wage needed to attract workers in a competitive labor market — equals marginal costs - decreased production and external safety purchases (Thaler and Rosen 1975). ${ }^{1}$ The canonical model treats workplace safety as exogenous to the worker. Only firms have the ability to change the workplace environment.

Intuitively, this distinction between workers and firms seems incorrect, as there may be opportunities for workers to affect the risk of accident and injury on the job that are unknown to firms, or too costly for firms to exploit. For example, consider that a quarter of fatal occupational injuries are the result of highway accidents. ${ }^{2}$ It is clearly possible, even likely, that drivers take action (invest) that are not possible for the firm to undertake to avert accidents. Drivers can be induced to take more or less investment in safety through payments such as safety bonuses. In this case, higher wages would be associated with fewer accidents, which is exactly the opposite of what standard theory predicts.

Compensation policies from industry support the notion that workers can individually invest in safety and are rewarded for such investment. Among the clearest examples of such policies are

\footnotetext{
${ }^{1}$ In this paper, we refer to "risk" and "safety" somewhat interchangeably, although risk and safety are the converse of each other.

${ }^{2}$ Census of Fatalities Occupational Injuries (2004)
} 
payments of bonuses for safety. Chappelle (1991) reports that firms offer monetary incentives to make workers more careful. Wilde (2000) notes that firms have been increasingly turning to safety incentive programs as a way to control accident costs. For example, in a survey of 40 long haul trucking firms in Canada, $70 \%$ of them have a safety incentive program. ${ }^{3}$ USA WASTE MANAGEMENT has a bonus pool that rewards employees with excellent safety records. ${ }^{4}$ Nationwide Insurance, Charter Communications and General Motors have programs that reward seat belt use. DENARK CONSTRUCTION's hourly employees receive a bonus check every quarter if their particular project avoids any serious OSHA citations, individual violations of company safety policies and accidents on that project. ${ }^{5}$ There are also many large consulting firms that advise employers on how to motivate employees to improve their safety behavior.

Several studies and anecdotal evidence suggest that bonuses are associated with reductions in accident rates. In a study that compared different methods of reducing accidents, Gregersen et al. (1996) finds that bonuses for safe driving significantly reduce the number of accidents and costs of accidents. Nafukho et al. (2004) examine the performance of tractor-trailer truck drivers in a U.S. trucking company and find that bonuses are associated with a reduction in accidents. Furthermore, some companies report client testimonials of how programs have reduced their accident rates and costs. ${ }^{6}$ In sum, there is widespread and growing use of paying employees for improved safety.

In this paper, we develop a model in which workers invest in workplace safety in addition to investments made by firms. The model has important implications for the relationship between safety and wages, and may help explain why there is inconclusive empirical evidence for the

\footnotetext{
${ }^{3} \mathrm{http} / / /$ www.tc.gc.ca/innovation/tdc/summary/13200/13256e.htm

${ }^{4}$ http://www.billsims.com/oshmag2.php

5 http://ehstoday.com/safety/incentives/ehs_imp_37524/index.html

${ }^{6}$ http://www.safetypays.com/clients2.html
} 
existence of compensating wage differentials (CWD), especially for nonfatal risk. ${ }^{7}$ The model we develop does not rely on the absence of a competitive labor market to explain the absence of a wage premium for risk of injury (Dorman and Hagstrom 1998). Our model predictions also have implications for estimates of the value of a statistical life (VSL) which are typically derived from CWD estimates.

The second part of the paper tests the model predictions empirically using NLSY data from 1992-2000, merged with BLS 3-digit occupational risk data. Our rich empirical models include a variety of individual-level covariates, along with hundreds of occupation fixed effects, industry fixed effects, year fixed effects as well as individual fixed effects. The empirical findings are absolutely in line with the model predictions. Most important, we obtain remarkably precise CWD estimates for nonfatal risk that coexist with a similarly strong negative association between individual accident risk and wages. As predicted by our model of endogenous worker safety investments, a safety disinvestment wage penalty is only found for high-risk occupations.

\section{Previous Literature}

Although not in a formal way, several previous CWD studies refer to heterogeneity in safety-related productivity. To incorporate this notion empirically, these studies typically include an interaction between a personal characteristic and a measure of job risk to assess whether the return to risk differs by the specific characteristic (Viscusi 1978; Gegax et al. 1991; Shogren and Stamland 2002; Kniesner et al. 2010; Kochi and Taylor 2012). Other studies have used seat belt use or cigarette smoking as proxies for heterogeneity in risk preferences, but also note that these variables may instead proxy for workers' safety-related productivity (Viscusi and Hersch 2001).

\footnotetext{
${ }^{7}$ Wage premiums for risk have been found more consistently for fatal risk, yet some studies do not find evidence of this either (see, e.g., Leigh 1991; Viscusi and Aldy 2003; Kniesner et al. 2012; Doucouliagos et al. 2012).
} 
An earlier literature recognizes the importance of worker behavior in affecting risk of accident (Oi 1974; Chelius 1974).

Only a few previous studies formally incorporate the idea of worker investments in safety (Rea 1981; Moore and Viscusi 1990; Krueger 1990; Lanoie 1991; 1994). We provide another model similar to those in these studies, but with some notable differences. In our model, even a fully insured worker makes investments in safety because safety investments increase worker productivity, thus firm profits, and as a result wages increase. Workers invest in safety for two reasons. As in previous models, such investments increase their utility by decreasing the probability of the hazardous state, which entails a personal financial loss. Such models, however, tend to focus on investments in safety only through the demand for it by workers (Seabury, Lakdawalla and Reville 2005). In contrast, our model incorporates a direct incentive for both firms and workers to demand investments in safety. This is because such investments are valuable to the firm regardless of workers preferences for wages, safety and WC benefits. ${ }^{8}$

In sum, previous studies generally do not formally incorporate or systematically analyze workers' investments in safety and their implications for the determination of wages and risk of accidents. Although the exception, some previous empirical studies implicitly recognize the issue, but usually discuss it in terms of worker heterogeneity in ability or preference for risk and analyze it in an ad-hoc way. Furthermore, there is considerable evidence that workers invest in a variety of productivity-enhancing skills and it is certainly plausible that some of those investments translate into skills that reduce accident risk. Finally, evidence from other contexts suggests consumers invest in safety. For example, increases in automobile insurance are associated with higher accident rates (Chiappori 2000), suggesting insurance reduces consumers' incentives to prevent them.

\footnotetext{
${ }^{8}$ Previous studies only focus on the safety of the worker, and accident costs faced by the firm are typically thought to be WC benefits and lower wage costs. However, firms may face direct costs of accidents. Consider the hedonic methodology used in previous empirical studies. In this approach, firms are sellers and workers are buyers of safety. Our model is different in that firms are not only sellers, but also buy safety produced by workers.
} 
In short, it is somewhat surprising that worker investments in safety have been largely overlooked in the literature; thus, a model allowing for such investments is warranted.

\section{A Model of Worker Investments in Safety}

\subsection{Worker's Incentives to Invest in Safety}

It is known that firms have an incentive to invest in safety because it lowers accident and wage costs, as workers are willing to accept lower wages for a lower risk of accidents. However, workers also have an incentive to invest in safety that is independent of the firm's objectives. Worker investments in safety increase utility by decreasing the probability of an accident and the associated loss of wages (Ehrlich and Becker 1972).

To make this point more formally, we begin by considering the worker's incentives drawing on the model by Ehrlich and Becker (1972). There is a probability $p$ that an accident occurs resulting in the worker's nonfatal injury, $0 \leq p<1$. Workers can make investment in safety, $e$, which will reduce the probability of an accident. ${ }^{9}$ The safety production function is $p(S, e, p)$, where $S$ is employer investments in safety and $p$ is the endowed risk of injury on a job that is determined by technology. We assume that $\frac{\partial p(S, e, p)}{\partial e}<0$, and $\frac{\partial^{2} p(S, e, p)}{\partial e^{2}}>0$, i.e., worker investments reduce the probability of an accident and there is decreasing marginal productivity of investment. The price of a unit of investment in safety is $q$. If there is no accident, the worker earns wage $W$ and his utility is $U(W-q e)$, where $U(\cdot)$ is a twice-differentiable, increasing and concave function. If there is an accident, there is a loss $l$, so worker's utility is $U(W-l-q e)$ in that state.

The worker's problem is to choose investments in safety, $e$, to maximize expected utility $E U$ as follows:

\footnotetext{
${ }^{9}$ Differentiating between general investment in safety and firm-specific investment in safety does not alter the results.
} 


$$
E U^{*} \equiv \max _{e} E U=[1-p(S, e, p)] U(W-q e)+p(S, e, p) U(W-q e-l)
$$

The first-order condition is given in equation (A3) (see Appendix B). The marginal benefit of worker safety investment—in form of a reduced accident probability — has to equal its marginal costs - in form of its price, $q$, weighted by the expected marginal utility of the accident and nonaccident state, respectively. Investment in safety will be higher the more productive workers are in producing safety and the lower is its cost $q$.

If the quantity of worker investments demanded by the firm exceeds the optimal level of investment that the worker would choose, the employer can induce further investments by compensating workers with higher wages. This wage change can be obtained formally by differentiating the expected utility function with respect to wages and worker investments to obtain

(2) $\frac{d W}{d e}=\frac{\frac{\partial p}{\partial e}\left(U_{1}-U_{0}\right)+q\left[(1-p) U_{1}^{\prime}+p U_{0}{ }^{\prime}\right]}{(1-p) U_{1}{ }^{\prime}+p U_{0}{ }^{\prime}} \geq 0$

Equation (2) shows the magnitude of the "safety-investment wage-premium", which is nonnegative.

\subsection{Firm's Incentives to Invest in Safety}

Now consider the firm's incentives to invest in safety $(S)$. Building on models by Smith (1974) and Oi (1974), we assume the employer produces output $Q$, which is an increasing function of labor $L, \frac{\partial Q(L)}{\partial L}>0, \frac{\partial^{2} Q(L)}{\partial L^{2}}<0$. The price of a unit of output is $m$. An accident can occur with probability $p$, and the safety production function is the same as above: $p(S, e, p)$. 
Accidents cost the firm $A$ dollars per worker, and include costs of training and replacing injured workers, lost production time of the victim and other workers, lost output and interrupted production. The price of a unit of firm investment in safety is $c$.

The firm has an incentive to induce worker investments in safety because this would increase profits. However, competition for workers would bid away these rents and they would have to be returned to the worker. Therefore, the employer would be willing to pay a higher wage for worker investments and would to do so until the wage increase for the last unit of investment equals the decrease in accident costs. ${ }^{10}$

To complete the firm's problem, we incorporate the constraint that the value of workers' utility resulting from firm choices is equal to the value of workers' utility that they can achieve on their own $\left(E U^{*}\right)$. The latter is obtained from the solution to the worker problem given by equation (1). This captures the idea that workers must be compensated for investing beyond their own optimal investment. The employer's problem is to choose labor $(L)$, investments in safety $(S)$, and worker investments in safety $(e)$ to maximize profits subject to a constraint that workers' utility is equal to $E U^{*}$ (the alternative):

$$
\begin{aligned}
& \max _{L, S, e} \pi=m Q(L)-W L-p(S, e, p) A L-c S L \\
& \text { s.t. }\left\{\left[E U^{*}=(1-p(S, e, p)) U_{1}(W-q e)+p(S, e, p) U_{0}(W-q e-l)\right] L\right\}
\end{aligned}
$$

Note that the employer does not incur the worker's cost (qe) of investment but compensates workers with higher wages for undertaking the investment. The first-order conditions

\footnotetext{
${ }^{10}$ To see this, consider the employer's profit function given by $\pi=m Q(L)-W L-p(S, e, p) A L-c S L$. Using the implicit function theorem, obtain an expression for the wage change needed to keep profits constant when workers invest in safety (i.e., zero profit constraint of competition) $\frac{d W}{d e}=-\frac{\partial p(S, e, p)}{\partial e} A>0$ This equation shows wages would rise in response to an increase in worker safety investments, where the magnitude of the wage increase would equal the expected reduction in accident costs. Note that worker investments in safety are no different than any other form of human capital investment. Investment raises worker productivity and is rewarded by higher wages. The magnitude of the wage increase would equal the expected reduction in accident costs.
} 
w.r.t. firm investments in safety $(S)$ and worker investments in safety $(e)$ are given by equations (A7) and (A8) in the Appendix. At the optimal level of employer investments in safety, marginal benefits have to equal marginal costs.

Differentiating equation (3) with respect to labor $(L)$, and solving for the wage $(W)$ yields a linear association between wages $(W)$, the injury risk $(p)$, and the firm costs of safety investment, $(c S)$ :

$$
W=m \frac{\partial Q(L)}{\partial L}-p(S, e, p) A-c S
$$

Equation (4) illustrates that wages depend on the level of employer and employee investments in safety through their effects on risk, $p$. Our empirical model will be mainly motivated by equations (4) and (2) above. Although firm-level safety investment and risk measures are not included in our dataset, we incorporate firm size dummies, a set of 417 occupational dummies at the 3-digit level, 236 industry dummies at the 2-digit level as well as year fixed effects. These variables should capture and represent the accident risk $(p)$ as well as firm safety investment costs $(c S)$ in equation (4) above. Note that one could easily reformulate the firm safety investment problem and aggregate up to the occupational or industry level.

In addition to their own safety investments, firms can induce worker investments in safety over and above the optimal level of worker safety investments as derived from equation (A3). As mentioned, this may be necessary and efficient since employers (a) cannot make these investments or (b) workers can make them more efficiently, i.e. $\frac{\partial p(S, e, p)}{\partial S}<\frac{\partial p(S, e, p)}{\partial e}<0$ and $q<=c$. Real world examples may be mining, logging, clerking or driving.

The wage increase required to keep worker utility constant when the worker invests in safety is given by equation (2). An alternative formulation is derived in the Appendix and given by: 
(5) $\frac{\partial p}{\partial e} A=-\frac{d W}{d e}\left[(1-p) U_{1}^{\prime}+p U_{0}^{\prime}\right] \chi$.

The left-hand-side of equation (5) represents the reduction in accident costs through the increased safety investment, i.e., the marginal benefit of worker investment in safety. The righthand-side of equation (5) is the wage increase required to compensate workers for their investment, weighted by their marginal utility of income and the value of changing utility by $\$ 1(\chi)$, i.e., the marginal cost of worker investment in safety.

As a final remark, note that our simple model does not allow for worker heterogeneity. Obviously, in reality and our data, there is variation of worker investment in safety at the individual level. Our model could generate this type of variation if one introduced heterogeneity and allowed worker safety productivities to differ across individuals. In a competitive labor market with heterogeneity in job risks, one would then need to introduce job search costs, mobility or switching costs to avoid complete worker sorting into different occupations. However, we decided to keep the model tractable.

\subsection{Summary of Theory and Predictions to be Tested in the Empirical Analysis}

The key insight of the model above is that workers can invest in safety and such investments raise the value of workers to the firm. Employers induce workers to make safety investments by paying for them with higher wages. These investments cannot be undertaken by the firm because it does not know about them, or finds it too costly to implement them.

An important prediction of this model is that the net effect of injury risk on wages is a priori ambiguous. The standard prediction is that the association between job risk and wages is clearly positive because firms offer CWDs to attract workers to accept risky jobs. This is true if risk is exogenously determined and cannot be influenced by workers. However, when workers can make 
the investment in safety, the association between wages and (worker-produced) risk is negative; firms pay workers higher wages to induce them to invest in safety and reduce risk.

The next section tests the model empirically. To derive testable predictions, we assume first that - from the perspective of the individual worker-nonfatal occupation injury risk is exogenously determined. Thus, across occupations, we hypothesize that there is (i) a positive correlation between occupational risk and wages since firms in higher risk occupations have to offer CWDs to attract workers.

However, in line with our model, we also assume that, second, workers can individually modify this exogenously given occupational injury risk through individual investments in safety. Hence, we hypothesize that there is (ii) a positive association between measures of worker investments in safety and wages. Since we employ an actual measure of disinvestment in safety, we expect to find a negative association between our measure of safety disinvestment and wages.

Third, we assume that the marginal benefit of worker investment in safety is higher in highrisk occupations. Thus, we hypothesize that (iii) the negative association between our measure of individual disinvestment in safety and wages is more pronounced in high risk occupations.

\section{Effect of Worker Investment in Safety on Wages: An Empirical Application}

Ideally, to test the theoretical model, we would need a direct measure of worker investment in safety, such as specialized safety equipment or specialized safety training. However, such measures are difficult to obtain. In this paper, we present an application afforded by mounting evidence that obesity increases the risk of accidents. ${ }^{11}$ Because obesity is to a significant degree individually modifiable, preventing it to reduce the risk of accidents can be thought of as an investment in self-protection or safety. Likewise we can think of becoming obese as some sort of

\footnotetext{
${ }^{11}$ See Guardado 2008; Pollack et al. 2007; Lakdawalla et al. 2007; Ostbye 2007; Finkelstein et al. 2007; Yoshino et al. 2006; Xiang et al. 2005; Corbeil 2001; Engkvist et al. 2000; Craig et al. 1998; Froom et al. 1996; Stoohs et al. 1994.
} 
disinvestment in human capital and safety. For example, the largest US employer, the US military, explicitly imposes weight-for-height and Percent Body Fat (PBF) standards for enlistment (Cawley and Maclean 2012).

At least three potential pitfalls should be kept in mind when using obesity as a proxy for individual (dis)investment in workplace safety: (a) it has been shown that obesity measures that are generated from self-reported height and weight measures include substantial measurement error and are not perfectly correlated with the real degree of body fat (cf. Burkhauser and Cawley 2009), (b) there is the possibility that obese workers are systematically more careful on the job since they are well aware of their higher injury risk. This could offset the higher injury risk induced by obesity, and (c) we should keep in mind that obesity is only an indirect proxy measure of worker disinvestment in safety. As noted above, we cannot exploit a direct worker investment measure such as hours of safety training. On the other hand, employing these direct measures would also require certain assumptions, e.g., effectiveness of the safety training or non-sorting into training participation.

There are several medical reasons why obese workers would be more prone to accidents. Obesity is associated with sleep apnea, which makes obese persons more likely to fall asleep or become drowsy while working (Browman et al., 1984; Strobel et al., 1996; Froom et al., 1996). Heavy persons are more likely to fall, particularly because of difficulty in controlling balance recovery in the anterior position (Corbeil et al. 2001). Moreover, obese persons have a hard time concentrating at work, which could be a "recipe for disaster, particularly for laborers working around machines" (Shutan 2003, p. 1039). The most suggested mechanisms underlying obese workers' higher risk of accidents are fatigue, sleepiness, physical limitations, ergonomics and poorer health (Pollack 2007). 
In essence, the main necessary condition that needs to hold when using obesity as a proxy for worker disinvestment in safety is that obese workers have a significantly higher risk of having an accident or injury on the job. This can be considered a stylized fact and has been shown by a growing body of the literature (Stoohs et al. 1994; Froom et al. 1996; Craig et al. 1998; Engkvist et al. 2000; Corbeil et al. 2001; Xiang et al. 2005; Yoshino et al. 2006; Finkelstein et al. 2007; Ostbye 2007; Lakdawalla et al. 2007; Pollack et al. 2007; Guardado 2008).

\subsection{Research Design and Methods}

For the empirical analysis, we use a simple linear specification motivated by equations (2) and (4) above.

$$
\begin{aligned}
& L n W_{i j k t}=\alpha_{i}+\pi_{j}+\sigma_{k}+X_{i t} \beta+\delta O B_{i t}+\gamma R I S K_{j}+\lambda\left(O B_{i t} * R I S K_{j}\right)+e_{i j k t} \\
\mathrm{i}=1, \ldots, \mathrm{N} & \text { (index of persons; } \mathrm{N}=7,006) \\
(6) \mathrm{j}=1, \ldots, \mathrm{J} & \text { (index of } 3 \text { - digit occupations; } \mathrm{J}=417) \\
\mathrm{k}=1, \ldots, \mathrm{K} & \text { (index of } 2 \text { - digit industries; } \mathrm{K}=217) \\
\mathrm{t}=1992, \ldots, 2000 & \text { (index of years) }
\end{aligned}
$$

In equation (6), $X$ is a vector of an extensive set of regional, demographic, educational as well as workplace characteristics (see Appendix A). These characteristics are expected to affect wages and should proxy for the price of worker investment in safety, worker productivity in producing safety investments, and worker preferences toward risk.

$\alpha_{i}, \pi_{j}$ and $\sigma_{k}$ are person, occupation and industry fixed effects, respectively. They proxy for workers' and firms' investment costs, accident costs as well as the productivity of their safety investments. Note that $X$ also includes firm size dummies.

$O B$ is a measure of obesity (body mass index $>30$ ). Note that $X$ additionally includes the plain and continuous BMI measure. This is to capture non-obesity-related weight effects. ${ }^{12}$ RISK is

\footnotetext{
${ }^{12}$ However, the results are robust to not including the continuous BMI measure.
} 
the nonfatal injury rate at the 3-digit occupational level per 100 full-time workers (FTW). It varies across the 417 occupations and over time between 1992 and 2000. $O B * R I S K$ is the interaction term between our safety disinvestment and risk measures and our main variable of interest.

Testing hypotheses. Recall the model predictions and the three derived hypotheses that we intend to test empirically with this model (see Section 3.3):

(i) First, across occupations we expect to find a positive association between occupational injury risk and wages since firms in higher risk occupations have to offer CWDs to attract workers. The plain RISK coefficient yields the CWD for riskier occupations; thus we expect $\gamma$ to be positive.

(ii) Second, we assume that workers can individually modify the exogenously given occupational injury risk through own investments in safety. We proxy for worker (dis)investment in safety with $O B$, i.e., becoming obese. Hence, we expect $\delta$ to be negative. Note that this association could also capture other underlying relationships between obesity and wages above and beyond worker safety investments and wages. One explanation could refer to discrimination. Another to the idea that obesity may be correlated with productivity that is not specific to reducing accident risk.

(iii) Third, and this represents the core idea of this paper, we hypothesize that the marginal benefit of worker investments in safety is higher in high-risk occupations. In other words, we aim to test whether becoming obese-which we see as an observable and individually modifiable disinvestment in human capital and safety-triggers a wage penalty that varies across the exogenously given occupational job risk. A priori, there is no reason to believe that any of the possible alternative explanations under (ii) which would explain a negative relationship between obesity and wages - e.g. discrimination — should differ significantly by job riskiness. Thus, the main coefficient of interest in equation (6) is the interaction term between obesity $(O B)$ and RISK. We expect $\lambda$ to be negative. 


\subsection{Data}

Data for the empirical analysis come from three sources. The primary source is the 1979 National Longitudinal Survey of Youth (NLSY). The NLSY is a sample of 12,686 people aged 14-22 years in 1979. The survey was conducted annually until 1994 and biennially thereafter. All the variables, with the exception of nonfatal injury and accident risk, were obtained from the NLSY.

Dependent variable. The dependent variable is the natural logarithm of the respondent's real hourly wage at his current/most recent job. We calculate the real hourly wage using the Consumer Price Index (CPI) for all urban consumers where the base period is 1982-1984. As shown in Appendix A, the average logarithm of the hourly wage is about $\$ 2$ (i.e., $\$ 7.50$ ). However, the smallest reported hourly wage was $\$ 1.05$ and the highest $\$ 56.83$. This illustrates that our dependent variable exhibits a significant degree of variation.

Obesity Measure. One key independent variable is obesity, which we calculate from the body mass index (BMI) using reported weight in each year and the reported height in $1985{ }^{13}$ We then create a dummy variable for obesity status $(\mathrm{BMI}>=30)$. The average $\mathrm{BMI}$ is 26.9 , but values range from 10.9 to 91.2 (see Appendix A). About $23 \%$ of all respondents are classified as obese. The evidence that high weight increases the risk of injury is mainly found for those who are obese (BMI $>=30)$, but not for those who are just overweight $(30>\mathrm{BMI}>=25)$.

Nonfatal Risk Measure. We obtained nonfatal injury rates by 3-digit occupation from the The Survey of Occupational Illnesses And InJuries (SOII) of the Bureau of Labor STATISTICS (BLS). ${ }^{14}$ The SOII provides information on nonfatal occupational injuries and illnesses

\footnotetext{
${ }^{13} B M I=K /\left(M^{2}\right)$, where $K$ is weight in kilograms and $M^{2}$ is height in meters squared.

${ }^{14}$ For $3 \%$ of all occupation-year observations, no risk rate measure could be assigned since no count of nonfatal injuries and diseases was available. Another reason we could calculate rates for just $97 \%$ of all observations is that there were
} 
resulting in at least one day away from work and on median days away from work due to injury. The SOII is a federal/state program in which reports are collected from private industry employers. State agencies collect and process the survey data and prepare estimates using standardized procedures established by the BLS to ensure uniformity and consistency between states. The data is available for the years 1992 to $2000 .^{15}$

To turn the risk counts into rates, we divide them by annual 3-digit occupation employment counts provided by the March CPS. In the following, we always report risk rates per 100 full-time workers (FTW). As Appendix A demonstrates, the variation in this crucial variable for our analysis is large and ranges from 0.006 to 102 nonfatal injuries or accidents per 100 FTW, occupation, and year. This risk measure is skewed to the right, with an average of 1.9 , a median of 1.1 , a $90^{\text {th }}$ quintile of 4.7 and a $99^{\text {th }}$ quintile of 10.5 .

Other Covariates. In our preferred specifications, we control for the following personal characteristics in addition to the individual fixed effects. The latter net out all time-invariant individual unobservables, which may confound simple OLS estimates.

A first category of controls refers to demographics and includes covariates such as age, gender, race, marital status, or \#kids in the household (see Appendix A).

A second category refers to education and includes dummies for high-school degree, some college education, or being a college graduate. We also split the Armed Forces Qualification Test Score (AFQT) into quartiles and include dummy variables for each quartile accordingly.

missing CPS employment counts. More specifically, for our time period covered, the CPS still used the 1980 Census Occupation Code, whereas the SOII used the 1990 Census Occupation Code. Despite crosswalks, the concordance is not perfect and not all codes could be matched. However, as a robustness check, we imputed 3-digit industry-specific risk measures for the missing values. The results are very robust.

${ }^{15} 1995,1997$, and 1999 are not covered. 
A third category of controls makes use of workplace characteristics and includes four firm size dummies (<=25, 26-99, 100-499, >500 employees), an indicator for whether there was a job change, and a dummy indicating whether the person holds a private or public sector job.

Finally, we also include regional controls for economic conditions and characteristics that may affect the value of the worker's marginal product (cf. Bender and Mridha, 2011), e.g. the local unemployment rate $(<=6 \%, 6$ to $8.9 \%,>9 \%)$ as well as the region of residence (northeast, north central, west and south; urban or rural residence).

Note that we always consider the survey year in form of year fixed effects. In more sophisticated models, we additionally incorporate a full set of 3-digit occupation fixed effects (417 dummies) as well as a full set of 2-digit industry fixed effects (236 dummies).

Sample Selection. We restrict the sample to those who worked for pay, worked at least 40 weeks in the year prior to the survey, usually worked at least 24 hours a week, were not selfemployed, were not in the armed forces, reported valid 3-digit occupation and 2-digit industry codes, had non-missing data on key variables, and did not have a real hourly wage less than $\$ 1$ or greater than $\$ 100 .^{16}$ We drop observations with extreme values of the real hourly wage as they are likely coding errors. After all restrictions, we have a sample of 26,016 person-year observations on 7,006 persons.

\section{Results}

\subsection{Descriptive Evidence}

We begin by showing mean values for obese vs. non-obese employees in Table 1. As can be inferred from this descriptive exercise, on average, obese people work in slightly riskier

\footnotetext{
${ }^{16} \mathrm{We}$ exclude those in the armed forces as is common in the previous literature. After the aforementioned selection restrictions, the following variables have missing data: wage $(\mathrm{N}=451)$, occupation $(\mathrm{N}=120)$, industry $(\mathrm{N}=163)$, weight or height (bmi) $(\mathrm{N}=710$.
} 
occupations. However, particularly given the huge standard deviation of RISK of 2.6, the differences in average injury risk per $100 \mathrm{FTW}$ are minor (1.9 vs. 2.0). It is also worthwhile to note that, on average, obese workers make less than non-obese workers (\$7.74 vs. \$6.97).

\section{[Insert Table 1 about here]}

However-and this may be surprising-overall, all relevant covariates seem to be reasonably well balanced. We do not find empirical evidence of worker sorting into occupations based on their obesity status. Imbens and Wooldridge (2009) propose to judge the covariate balance based on the scale-free "normalized difference" (see notes to Table 1 for more details). According to their rule of thumb, values below 0.25 suggest a well covariate balance. Column (3) of Table 1 shows that all normalized differences are significantly below 0.25 ; for most variables, the values are even below 0.1. For example, consider the indicator for whether or not employees changed their job. For various reasons, one might suspect that obese workers switch jobs more often. The difference in the job switching rate is, however, minor and even lower for the obese $(24.6 \%$ vs. $23.6 \%)$; the normalized difference is only 1.6 .

Table 2 now differentiates by job risk. The first column header of Panel A indicates the nonfatal risk quartiles. In each quartile, i.e. across the whole risk distribution, we have enough observations for obtaining statistical precision and they are also surprisingly balanced; each quartile counts between 5,000 and 6,500 observations. The second column header differentiates by obesity status. The first row indicates the hourly wage. Panel A lets us conclude the following:

(I) The wage seems to strictly decrease with the risk level of the job. This is not in line with our hypothesis (i) above and the standard finding of the CWD literature. However, one should keep in mind that these are simple descriptive correlations. 
(II) Obese workers make less than non-obese workers in each risk category. This is in line with our hypothesis (ii) above. It is also in line with the previous literature on the obesity-wage relationship (Cawley, 2004; Lindeboom et al., 2010; Kan and Lee, 2012; Sabia and Rees, 2012).

(III) The wage differential between obese and non-obese workers decreases with job risk both in absolute and relative terms. This purely descriptive finding is also at odds with our hypothesis (iii) above.

\section{[Insert Table 2 about here]}

In Panel B of Table 2, we now look at changes instead of levels and compare workers who become obese to workers who do not - again by risk category. We do not only look at changes in weight, but also at changes in wages as indicated by the row. We find the following:

(I) Again, as above in Panel A, wage growth seems to slow down, the higher the risk category. However, the relationship is far less pronounced than when looking at the variables in levels. In addition, in a statistical sense, there are no differences in wage growth across risk categories.

(II) The wage growth for workers who become obese is not statistically different from the wage growth for workers who keep their weight. This finding holds across all risk categories.

(III) The wage growth differential between weight gainers and weight keepers does not differ statistically across the different risk categories. The mean values for the two worker groups within a risk category are almost identical. However, just looking at simple means, one finds that the differential wage growth is slightly larger for lower risk as compared to higher risk categories.

\subsection{Evidence from Standard Regression Models}

Table 3 shows the results of different regression models as illustrated by equation (6). The first three columns report the findings for a simple OLS regression model that correlates the natural 
logarithm of the hourly wage with level measures of the BMI, obesity, nonfatal risk as well as the interaction between $O B$ and RISK. The three columns only differ by the inclusion of sets of covariates as indicated in the bottom of the table. Column (1) only considers year fixed effects and is, except for correcting for year shocks, the regression analogue to Panel A of Table 2.

Column (2) incorporates a rich set of 417 occupation and 236 industry fixed effects. Essentially, this means that we net out persistent wage differences across industries and occupations. We also net out all other time-invariant occupational and industry factors, observable and unobservable, that may confound the statistical relationship between wages, job risk, and obesity. For example, although we have not found evidence for this in Table 1, it may plausible for obese workers to self-select into specific occupations and/or industries with structurally different wage levels. The descriptive associations in Table 2 may be an artifact of such sorting.

Column (3) of Table 3 additionally controls for a rich array of individual-level controls with respect to demographics, education, and the workplace (see Appendix A). Such individual-level factors may likewise confound the relationship between wages, on the job risk, and obesity. Note that the $\mathrm{R}^{2}$ strongly increased from 0.05 in column (1) to 0.41 and 0.52 in columns (2) and (3). This means that we employ an unusually rich microdata model that may explain more than $50 \%$ of the cross-sectional wage variation in levels.

We find the following from the first three columns of Table 3:

(I) Only in the most parsimonious specification, in column (1), we find that higher injury risk is negatively correlated with wages. Again, this is the regression analogue to Panel A of Table 2. We see that workers in occupations with 1 additional injury per 100 FTW make $3.5 \%$ lower wages. One additional injury per 100 FTW represents an increase of about $50 \%$ of the variable mean. However, once we net out persistent differences across occupations and industries in columns (2) and (3), this statistical association vanishes. 
(II) Obese workers have a lower wage, independent of their occupational risk. However, the wage penalty decreases from $14 \%$ in column (1) to $4 \%$ in column (3). Overall, this negative statistical correlation is in line with our hypothesis (ii) above. Note that BMI in levelsindependent of obesity status - is positively correlated with wages. This may be due to the fact that sick people are typically underweight and that the health/productivity-BMI relationship is certainly nonlinear.

(III) Once we consider occupation and industry fixed effects, obese workers seem to have a significantly $0.8 \%$ higher wage when increasing the injury risk by 1 injury per 100 FTW. However, one needs to consider that-in general—obese workers have a $4 \%$ lower pay. Hence, overall, this still yields a wage penalty for obese workers. However, obese workers still seem to be relatively better off in high-risk occupations. This is not in line with our hypothesis (iii).

\section{[Insert Table 3 about here]}

In columns (4) to (6) of Table 2, we likewise include sets of covariates in a stepwise fashion. However, in contrast to columns (1) to (3), we now consider individual fixed effects. This is important since now we look at changes in obesity rather than levels. In other words, the effects are identified by individuals who experience a weight change; in this case, by those who become obese. This is an important distinction to the simple OLS model since it nets out all time-invariant unobservables that may be correlated with both obesity and wages and that may lead to spurious statistical correlations. We find the following when we employ these more sophisticated specifications.

(I) Workers in high risk occupations make more money, in our preferred specifications in columns (4) to (6), 5\% to $6 \%$ more. This finding is in line with our hypothesis (i). Note that this positive wage differential is identified by workers who either switch occupations or whose occupations become riskier over time and who thus see a change in their occupational risk. It also 
illustrates that the zero or even negative finding of the OLS model in columns (1) to (3) is spurious. The existence of a CWD for higher risk jobs has been demonstrated by numerous studies in the economics literature (cf. Viscusi and Aldy, 2003).

(II) The general statistical association between obesity and wages vanishes. However, interestingly, the positive association between BMI and wages is persistent. Note that the zero finding for obese people does not contradict our hypothesis (ii). This is a finding independent of the job risk and holds for the average obese person. For example, assume that obese people only experience a wage penalty in high risk jobs but not in jobs without risk. Further assume that many obese people work in low risk jobs. Then the non-significant relationship between obesity and wages may be the consequential statistical result for the average obese person.

(III) Our main variable of interest, the interaction term between obesity and job risk, is highly significant and negative. It suggests that becoming obese reduces wages by about $0.4 \%$ but only in high risk jobs. By excluding job changers we show in a robustness check below that this is not due to an alternative explanation which would refer to obese workers who switch jobs. The finding that becoming obese leads to a wage penalty only in high risk jobs is absolutely in line with our model and hypothesis (iii).

A highly significant wage penalty of $0.4 \%$ appears to be small in magnitude; however, it translates into $\$ 200$ per year for an annual income of $\$ 50,000$. After a work life of 30 years and assuming a $2 \%$ discount rate, this yields a lifetime wage penalty of more than $\$ 8,000$.

\subsection{Robustness Checks}

As a first robustness check, we exclude workers who changed their jobs. Recall that the negative effect of the $O B^{*} R I S K$ may either stem from workers who become obese or from obese

workers who switch jobs and sort into occupations. We have already seen in Table 1 that the 
covariates between obese and non-obese workers are very well balanced. This supports the view that the negative association is not a result of worker sorting. Now we exclude the possibility that the finding in column (6) of Table 3 may be a result of obese workers switching jobs. Excluding workers who switched jobs yields a surprisingly robust and highly significant negative relationship between becoming obese, job risk, and wages (column (1), Table 4). Becoming obese results in a wage penalty of about $0.5 \%$ for higher risk jobs; more specifically, for a risk rate increase of one additional injury per 100 FTW.

\section{[Insert Table 4 about here]}

In column (2) of Table 4, we use lagged values of all variables. Our main coefficient of interest-OB*RISK-shrinks, but remains significant at conventional statistical levels. The shrinking of the coefficient makes sense since the NLYS does not include the years 1995, 1997, and 1999. This means that, for 1996, 1998 and 2008, a lag is actually a lag of two years, not just one, and the obesity-risk-wage association thus decreases over time.

In column (3), we cluster at the occupation instead of the individual level (Bertrand et al. 2004), but the estimates remain largely significant.

\subsection{Heterogeneity in Effects}

Next we explore whether there is heterogeneity in the effects. First, we test whether the results differ by gender. To do that, we generate and add an additional triple interaction term between female and $O B^{*} R I S K$ to the model. If our obesity measure is capturing safety-related productivity, then we should not expect to find a differential. Other evidence finds that obesity increases the risk of accidents for both males and females (e.g., Guardado 2008). Thus, we do not expect to find a differential by gender. If we did, that might suggest the obesity penalty might be due to other factors, if, say, obese women were discriminated against more in risky job. Column (4) 
of Table 4 shows that there is no evidence that the result differ by gender. This bolsters the idea that the wage penalty is due to lower safety-related-productivity.

Next, we test whether the results differ by race and add two triple interaction terms between the dummies black and Hispanic, respectively, to the model. Similar arguments to those we made above with respect to obesity apply here as well. All workers - in this case across race-ethnicity status - are at higher risk of accidents when they are obese. Again, we do not find any evidence that the results differ by race. ${ }^{17}$

In column (5), we interact age with $O B^{*} R I S K$ and add this triple interaction term to the model. Note that all respondents are between 27 and 43 years old. Nevertheless, we find a marginally significant and negative triple interaction suggesting that the high risk job wage penalty increases by $0.4 \%$ for every 5 life years (and presumably work experience). Put differently, the return to worker investment in safety increases with age.

\subsection{The Role of Job Requirements}

Thus far we looked at accident rates across occupations and over time. However, physically demanding job characteristics-e.g. strenuousness - should be one actual channel of transmission of the risk-obesity-wage relationship, since they increase the risk of accidents. Strenuousness may make obese workers less productive and increase the risk of an injury on the job.

To investigate this possibility, we generate a variable "JobPhysicallyDemanding." This variable takes on values from 1 to 3 and varies across occupations. It indicates whether the job requires (i) climbing, (ii) reaching, or (iii) stooping, kneeling, crouching or crawling. ${ }^{18}$ Then, we

\footnotetext{
${ }^{17}$ Results are not displayed in Table 4 and available upon request.

${ }^{18} \mathrm{We}$ assigned these job characteristics to the occupations in the NLSY using the Dictionary of Occupational Titles (DOT), Revised Fourth Edition, following the work of Lakdawalla and Philipson (2009). This consisted of first matching 1990 US Census occupation codes (used in the NLSY) to the occupations in the DOT, and then assigning DOT scores to the US Census occupation codes. Because DOT occupations can be more narrow and specific than the
} 
add this variable in levels along with a triple interaction term to our standard model. We hypothesize that the wage penalty for obese workers in high risk occupation is particularly pronounced in jobs with these physical requirements since they obviously increase the accident risk.

The results from this exercise are in column (6) of Table 4 and exactly in line with our expectations. The triple interaction term is significant at conventional levels and of the same size as the $O B^{*} R I S K$ coefficient in Table 3, column (6). Note that the $O B^{*} R I S K$ coefficient in this model is no longer significant. This illustrates nicely that the obesity-wage-penalty is not only specific to high-risk occupations, but also to high-risk occupations that require physically demanding work such as climbing, reaching, or stooping. This is strongly in line with our model and our hypothesis: becoming obese indicates a depreciation of human capital which translates into a decrease in wages, but only in high risk and physically demanding jobs.

\section{Summary and Conclusions}

The standard economic theory of compensating wage differentials (CWDs) assumes that firms and workers face tradeoffs between risk of accident and wages. Firms can pay higher wages to compensate workers for accepting this risk, or they can invest in safety to lower the wages they pay. Importantly, that model makes the strong assumption that risk is exogenous to workers, as only firms can reduce risk. We depart from most past research by incorporating worker investments in safety. A key prediction of the new model is that the risk will be positively associated with wages only to the extent it is produced by the firm or determined by technology. However, if risk is produced by workers, then greater risk is associated with lower wages.

Census occupations - Census occupations can match to multiple DOT occupations-we averaged the DOT scores within each 1990 US Census code to obtain an average score for each Census code. We were unable to assign job characteristics for 147 individuals. 
To derive testable implications, we assume that occupational injury risk is exogenously given but that the individual worker can influence the risk through individual investments in safety. We test the following three hypotheses empirically: (i) Across occupations, which differ by injury risk over time, the association between risk and wages is positive since employers need to pay CWDs to attract workers. (ii) In contrast, individual-level safety investments are positively associated with wages, i.e., at the individual level, risk is negatively associated with wages. (iii) The positive association between changes in worker investment in safety and wages is more pronounced in high-risk occupations.

We test our three hypotheses empirically using NLSY data from 1992 to 2000 and detailed BLS nonfatal risk measures at the annual 3-digit occupation level. As a proxy for worker-specific safety (dis)investment, we use obesity. Previous evidence finds that obesity increases the risk of accidents; thus, because obesity is an individually modifiable attribute, weight control can be thought of as an investment in self-protection or safety (Kenkel 2000).

Our empirical results are both in line with our three hypotheses and the previous literature. Most important, we find a highly significant negative relationship between obesity, job risk, and wages. When workers become obese, they face a wage penalty of about $1.5 \%$ in a high risk as compared to a median risk occupation $\left(90^{\text {th }}\right.$ vs. $50^{\text {th }}$ risk percentile). For every additional injury per $100 \mathrm{FTW}$ and year, the wage penalty for obese workers increases by about $0.5 \%$.

It is worthwhile to stress that we obtain a remarkably precisely estimated positive relationship between occupational risk and individual wages - this is the standard CWD finding. However, we obtain it with precision for nonfatal risk in a rich model that, besides others, includes individual, occupational and industry fixed effects. As mentioned above, we disentangle from this positive risk-wage relationship another precisely estimated negative association between a measure of individual accident risk and wages. The latter additionally varies by overall workplace risk, in 
line with our model, and has the same size as the standard CWD estimate. In an extension of our standard model, we show that the transmission channel is related to job requirements since becoming obese only leads to a wage penalty in strenuousness high risk jobs.

By showing that the covariates between obese and non-obese workers are well balanced and by excluding job changers in a robustness check, we provide strong evidence against the notion that the wage penalty for obese workers in high risk occupations is a result of sorting. We also address concerns that omitted variable bias might produce our findings by incorporating a very rich set of year fixed effects, hundreds of occupational and industry fixed effects, personal and regional covariates as well as individual fixed effects. Ultimately, the empirical effect is identified by workers who are at least observed twice in our panel data, become obese and do not change jobs.

However, to be cautious, we do not interpret our findings as strict causal evidence, but as strongly in line with our model predictions and the idea of worker investment in safety. After all, we do not have a direct measure of worker investment in workplace safety, but only a proxy. However, this proxy is highly correlated with accidents, is modifiable by the worker, and thus varies at the individual level. Alternative stories about time-varying unobservables that are correlated with wages, obesity, and occupational risk are perhaps imaginable, but we consider the probability of their real-life relevance as minor. For example, a priori, there is no reason to believe that discrimination of obese workers should significantly differ by occupational job risk. We suspect that measuring the effects of more direct measures of worker investments in safety might yield larger estimates than those we identify here. We intend to head in this direction of inquiry and encourage other researchers to do the same.

In summary, our empirical evidence suggests that obese workers earn lower wages particularly in physically demanding high risk occupations. More generally, the results of this study are consistent with models in which workers invest in safety and firms pay higher wages for these 
investments. Worker investments in safety will generate a negative relationship between wages and overall workplace risk, which is the opposite prediction from the standard CWD argument. Failing to account for this possibility may be one explanation for varying and imprecisely estimated CWDs findings. To the extent that these results carry over to fatal risk, they also suggest that VSL estimates may be severely biased. 


\section{References}

Bender, Keith A., and Hosne Mridha, 2011. "The Effect of Local Area Unemployment on Compensating Wage Differentials for Injury Risk." Southern Economic Journal, 78 (2): 287307.

Bertrand, M., Duflo, E. and Sendhil Mullainathan. 2004."How Much Should We Trust Differencesin-Differences Estimates?" The Quarterly Journal of Economics, 119(1): 249-275.

Browman, Carl P., Michael G. Sampson, Stanley F. Yolles, Krishnareddy S. Gujavarty, Stephen J. Weiler, Joyce A. Walsleben, Pierre M. Hahn, and Merrill M. Mitler. 1984. "Obstructive Sleep Apnea and Body Weight." Chest. 85 (3): 435-438.

Burkhauser, Richard V., and John Cawley. "Beyond BMI: The Value of More Accurate Measures of Fatness and Obesity in Social Science Research." Journal of Health Economics, 2008, 27(2): 519-529.

Cawley, John. 2004. "The Impact of Obesity on Wages." Journal of Human Resources. 39 (2): 451-472.

Cawley, John, and Johanna Catherine Maclean, 2012. "Unfit For Service: The Implications Of Rising Obesity For Us Military Recruitment." Health Economics. 21 (11). 1348-1366.

Chappell, Kevin. 1991. "Boss, I Feel Lousy. Where's my check? The Trouble with Workers' Compensation." Business Week. (July): 25-26.

Chelius, James, R. 1974. "The Control of Industrial Accidents: Economic Theory and Empirical Evidence." Law and Contemporary Problems. 38 (4): 700-729.

Chiappori, Pierre A. 2000. "Econometric Models of Insurance Under Asymmetric Information." In Handbook of Insurance, edited by Georges Dionne. London: Kluwer Academic Publishers.

Corbeil, Philippe, Martin Simoneau, Denis Rancourt, Angelo Tremblay, and Normand Teasdale. 2001. "Increased Risk for Falling Associated with Obesity: Mathematical Modeling of Postural Control." Neural Systems and Rehabilitation Engineering. 9 (2): 126-136.

Craig, Brian N., Jerome J. Congleton, Carter J. Kerk, John M. Lawler, and Kevin P. McSweeney. 1998. "Correlation of Injury Occurrence Data with Estimated Maximal Aerobic Capacity and Body Composition in a High-Frequency Manual Materials Handling Task." American Industrial Hygiene Association Journal. 59 (1): 25-33.

Dorman Peter and Paul A. Hagstrom. 1998. "Work Compensation for Dangerous Work Revisited." Industrial and Labor Relations Review. 52 (1): 116-135.

Doucouliagos, Chris, T.D. Stanley, Margaret Giles. 2012. "Are estimates of the value of a statistical life exaggerated?" Journal of Health Economics. 31 (1): 197-206. 
Ehrlich, Isaac and Gary S. Becker. 1972. "Market Insurance, Self-Insurance and SelfProtection." Journal of Political Economy. 80 (4): 623-648.

Engkvist, Inga-Lill, Ewa W. Hjelm, Mats Hagberg, Ewa Menckel, and Lena Ekenvall. 2000. "Risk Indicators for Reported Over-Exertion Back Injuries among Female Nursing Personnel." Epidemiology. 11 (5): 519-522.

England, Paula and Barbara S. Kilbourne. 1998. Occupational Measures from the Dictionary of Occupational Titles for 1980 Census Detailed Occupations. Ann Arbor, MI: Inter-university Consortium for Political and Social Research.

Finkelstein, Eric A., Hong Chen, Malavika Prabhu, Justin G. Trogdon, Phaedra S. Corso. 2007. "The Relationship between Obesity and Injuries among U.S. Adults." American Journal of Health Promotion. 21 (5): 460-468.

Froom, Paul, Samuel Melamed, Estela Kristal-Boneh, Daphne Gofer, and Joseph Ribak. 1996. "Industrial Accidents are related to Relative Body Weight: The Israeli CORDIS Study." Occupational and Environmental Medicine. 53 (12): 832-835.

Gegax, Douglas, Shelby Gerking, and William Schulze. 1991. "Perceived Risk and the Marginal Value of Safety." The Review of Economics and Statistics. 73 (4): 589-596.

Guardado, José. 2008. "The Effects of Worker Investments in Safety on Risk of Accidents and Wages." Dissertation., University of Illinois at Chicago.

Kan, Kamhon, and Myoung-Jae Lee. 2012: "Lose weight for a raise only if overweight: Marginal integration for semi-linear panel models. Journal of Applied Econometrics. 27 (4): 666-685.

Kenkel, Donald. 2000. "Prevention." In Handbook of Health Economics, edited by Anthony J. Culyer, and Joseph P. Newhouse. North-Holland: Elsevier.

Kniesner, Thomas J., W. Kip Viscusi, and James Ziliak, 2010. "Policy relevant heterogeneity in the value of statistical life: New evidence from panel data quantile regressions," Journal of Risk and Uncertainty. 40 (1): 15-31.

Kniesner, Thomas J., W. Kip Viscusi, Christopher Woock, and James P. Ziliak, 2012. "The Value of a Statistical Life: Evidence from Panel Data," The Review of Economics and Statistics. 94 (1): 74-87.

Kochi, Ikuho, Laura O. Taylor. 2011. "Risk Heterogeneity and the Value of Reducing Fatal Risks: Further Market-Based Evidence" Journal of Benefit-Cost Analysis. 2 (3): Article 1.

Krueger, Alan B. 1990. "Incentive Effects of Workers' Compensation Insurance." Journal of Public Economics. 41 (1): 73-99.

Lakdawalla, Darius N., Robert T. Reville, and Seth A. Seabury. 2007. "How Does Health Insurance Affect Workers' Compensation Filing?" Economic Inquiry. 45 (2): 286303. 
Lakdawalla, Darius N., Philipson, T. 2009. "The Growth of Obesity and Technological Change," Economics and Human Biology, 7 (3): 283-293.

Lanoie, Paul. 1991. "Occupational Safety and Health: A Problem of Double or Single Moral Hazard." Journal of Risk and Insurance. 58 (1): 80-100.

. 1994. "A Note on Government Intervention in Occupational Safety and Health: The Case for an Accident Tax and a Safety Bonus Scheme." Bulletin of Economic Research. 46 (2): 185-191.

Leigh, J. Paul. 1991. "No Evidence of Compensating Wages for Occupational Fatalities. Industrial Relations. 30 (3): 382-395.

Moore, Michael J., and W. Kip Viscusi. 1990. Compensation Mechanisms for Job Risks: Wages, Workers' Compensation, and Product Liability. Princeton, NJ: Princeton University Press.

Lindeboom, Maarten, Petter Lundborg, and Bas van der Klaauw. 2010. "Assessing the impact of obesity on labor market outcomes.” Economics \& Human Biology 8 (3): 309-319.

Oi, Walter Y. 1974. "On the Economics of Industrial Safety." Law and Contemporary Problems. 38 (4): 669-699.

Ostbye, Truls, John M. Dement, and Katrina M. Krause. 2007. "Obesity and Workers' Compensation: Results from the Duke Health and Safety Surveillance System." Archives of Internal Medicine. 167 (8): 766-773.

Pollack, Keshia M., Gary S. Sorock, Martin D. Slade, Linda Cantley, Kanta Sircar, Oyebode Taiwo, and Mark R. Cullen. 2007. "Association Between Body Mass Index and Acute Traumatic Workplace Injury in Hourly Manufacturing Employees." American Journal of Epidemiology. 166 (2): 1-8.

Rea, Samuel A. 1981. "Workmen's Compensation and Occupational Safety Under Imperfect Information." American Economic Review. 71 (1): 80-93.

Sabia, Joseph J., and Daniel I. Rees. 2012. "Body weight and wages: Evidence from Add Health." Economics \& Human Biology. 10 (1): 14-19.

Seabury, Seth A., Darius Lakdawalla, and Robert T. Reville. 2005. "The Economics of Integrating Injury and Illness Prevention and Health Promotion Programs." RAND Working 243, RAND, Santa Monica.

Shutan, B. 2003. "Obesity Debate Weighs on Workers' Compensation." Risk and Insurance. 5 (4):1039 Accessible at http://www.hreonline.com/HRE/view/story.jhtml?id=8101285.

Shogren, Jason F., Tommy Stamland. 2002. "Skill and the Value of Life," Journal of Political 
Economy. 110 (5): 1168-1197.

Stoohs, Riccardo A., Christian Guilleminault, Anna Itoi, and William C. Dement. 1994.

"Traffic Accidents in Commercial Long-Haul Truck Drivers: The Influence of SleepDisordered Breathing and Obesity." Sleep. 17 (7): 619-623.

Strobel, Richard J., and Raymond C. Rosen. 1996. "Obesity and Weight Loss in Obstructive Sleep Apnea: A Critical Review. Sleep. 19 (2): 104-15.

Thaler, Richard, and Sherwin Rosen. 1975. "The Value of Saving a Life. In Household Production and Consumption, edited by Nestor Terleckyj. New York, NY:NBER/Columbia University Press.

Viscusi, W. Kip. 1978. "Labor Market Valuations of Life and Limb: Empirical Evidence and Policy Implications." Public Policy. 26 (3): 359-386.

Viscusi, W. Kip, and Joni Hersch. 2001. "Cigarette Smokers as Job Risk Takers." The Review of Economics and Statistics. 83 (2): 269-280.

Viscusi, W. Kip, Aldy, Joseph E., 2003. "The Value of a Statistical Life: A Critical Review of Market Estimates throughout the World," Journal of Risk and Uncertainty, 27 (1): 5-76.

Wilde, Gerald J.S. 2000. "Enhancing Workers' and Drivers' Interest in their Own Safety." G.J.S. Enhancing Workers' and Drivers' Interest in their Own Safety." Proceedings, MAA Young Drivers Seminar, Sydney, NSW, Australia, March 31, 2000.

Xiang, Huiyun, Gary A. Smith, J. R. Wilkins III, Guanmin Chen, Sarah G. Hostetler, and Lorann Stallones. 2005. "Obesity and Risk of Nonfatal Unintentional Injuries." American Journal of Preventive Medicine. 29 (1): 41-45.

Yoshino, Akiko, Maki Higuchi, Fusae Kawana, Mitsue Kato, Minae Kamata, Shigemoto Nakanishi, Takatoshi Kasai, and Koji Narui. 2006. "Risk Factors for Traffic Accidents in Patients with Obstructive Sleep Apnea Syndrome." Sleep and Biological Rhythms. 4 (2): 144155. 
Table 1: Balancing Properties of Covariates by Obesity Status

\begin{tabular}{|c|c|c|c|}
\hline Variables & Obese $=0$ & Obese $=1$ & $\begin{array}{c}\text { Normalized } \\
\text { difference }\end{array}$ \\
\hline \multicolumn{4}{|c|}{ Dependent variable } \\
\hline lnwage & 2.046 & 1.942 & \\
\hline \multicolumn{4}{|c|}{ Main variables of interest } \\
\hline nonfatalrisk & 1.870 & 2.005 & 0.037 \\
\hline emp & $1,001,527$ & $1,029,538$ & 0.016 \\
\hline bmi & 24.622 & 34.497 & 1.839 \\
\hline \multicolumn{4}{|c|}{ Demographic controls } \\
\hline age & 34.181 & 34.966 & 0.155 \\
\hline female & 0.444 & 0.446 & 0.004 \\
\hline hispanic & 0.177 & 0.220 & 0.075 \\
\hline black & 0.252 & 0.361 & 0.169 \\
\hline numkidshh & 1.210 & 1.338 & 0.074 \\
\hline mar & 0.571 & 0.559 & 0.018 \\
\hline nevmar & 0.223 & 0.257 & 0.057 \\
\hline \multicolumn{4}{|c|}{ Educational controls } \\
\hline lths & 0.095 & 0.121 & 0.059 \\
\hline hsgrad & 0.429 & 0.471 & 0.060 \\
\hline somecol & 0.231 & 0.252 & 0.035 \\
\hline colgrad & 0.245 & 0.156 & 0.159 \\
\hline afqt2 & 0.256 & 0.257 & 0.001 \\
\hline afqt3 & 0.212 & 0.183 & 0.051 \\
\hline afqt4 & 0.181 & 0.114 & 0.134 \\
\hline \multicolumn{4}{|c|}{ Workplace controls } \\
\hline gov & 0.096 & 0.125 & 0.064 \\
\hline fsize1 & 0.332 & 0.316 & 0.024 \\
\hline fsize 2 & 0.220 & 0.229 & 0.016 \\
\hline fsize3 & 0.228 & 0.238 & 0.017 \\
\hline fsize4 & 0.186 & 0.181 & 0.008 \\
\hline chjob & 0.246 & 0.236 & 0.016 \\
\hline \multicolumn{4}{|c|}{ Reqional controls } \\
\hline northe & 0.161 & 0.148 & 0.027 \\
\hline northc & 0.244 & 0.233 & 0.018 \\
\hline south & 0.391 & 0.438 & 0.067 \\
\hline west & 0.192 & 0.170 & 0.042 \\
\hline msregion & 0.011 & 0.012 & 0.006 \\
\hline msrura & 0.011 & 0.012 & 0.007 \\
\hline rural & 0.218 & 0.256 & 0.064 \\
\hline uerate2 & 0.355 & 0.321 & 0.052 \\
\hline uerate 3 & 0.152 & 0.151 & 0.003 \\
\hline
\end{tabular}

Source: NLYS and SOII 1992-2000; the last column shows the normalized difference which

has been calculated according to $\Delta \mathrm{s}=\left(\overline{s_{1}}-\overline{s_{0}}\right) / \sqrt{\sigma_{1}^{2}+\sigma_{0}^{2}}$ with $\overline{s_{1}}$ and $\overline{s_{0}}$ denoting average covariate values for obese and non-obese workers, respectively. $\sigma$ stands for the variance. As a rule of thumb, normalized differences exceeding 0.25 indicate non-balanced observables that might lead to sensitive results (Imbens and Wooldridge, 2009) 
Table 2: Descriptive Statistic of the Association between Job Risk, Wages, and Obesity Changes

\begin{tabular}{|c|c|c|c|c|c|c|c|c|}
\hline \multirow[t]{3}{*}{ Panel A } & \multirow{2}{*}{\multicolumn{2}{|c|}{ risk $<$ p25 }} & \multirow{2}{*}{\multicolumn{2}{|c|}{ p25 $<$ risk $<$ p50 }} & \multirow{2}{*}{\multicolumn{2}{|c|}{ p50 $<$ risk $<$ p75 }} & \multirow{2}{*}{\multicolumn{2}{|c|}{ risk > p75 }} \\
\hline & & & & & & & & \\
\hline & Obese & non-obese & obese & non-obese & obese & non-obese & obese & non-obese \\
\hline \multirow{3}{*}{$\begin{array}{c}\text { Real hourly wage } \\
\text { std. dev. } \\
N\end{array}$} & 10.07 & 11.57 & 7.91 & 9.09 & 7.34 & 7.79 & 6.83 & 7.15 \\
\hline & $(6.18)$ & $(7.31)$ & (4.19) & $(5.65)$ & $(4.21)$ & (4.39) & (3.17) & (3.34) \\
\hline & 1,250 & 5,130 & 1,435 & 5,197 & 948 & 3,990 & 1,622 & 4,868 \\
\hline \multicolumn{9}{|l|}{ Panel B } \\
\hline & \multicolumn{2}{|c|}{ risk $<$ p25 } & \multicolumn{2}{|c|}{ p25 $<$ risk $<$ p50 } & \multicolumn{2}{|c|}{ p50<risk $<$ p75 } & \multicolumn{2}{|c|}{ risk $>$ p75 } \\
\hline & $\begin{array}{l}\text { became obese } \\
\text { btw. } t_{0} \text { and } t_{1}\end{array}$ & $\begin{array}{l}\text { no obesity change } \\
\text { btw. } t_{0} \text { and } t_{1}\end{array}$ & $\begin{array}{l}\text { became obese } \\
\text { btw. } t_{0} \text { and } t_{1}\end{array}$ & $\begin{array}{l}\text { no obesity change } \\
\text { btw. } t_{0} \text { and } t_{1}\end{array}$ & $\begin{array}{l}\text { became obese } \\
\text { btw. } t_{0} \text { and } t_{1}\end{array}$ & $\begin{array}{l}\text { no obesity change } \\
\text { btw. } t_{0} \text { and } t_{1}\end{array}$ & $\begin{array}{l}\text { became obese } \\
\text { btw. } t_{0} \text { and } t_{1}\end{array}$ & $\begin{array}{l}\text { no obesity change } \\
\text { btw. } t_{0} \text { and } t_{1}\end{array}$ \\
\hline \multirow{2}{*}{\multicolumn{9}{|c|}{$\begin{array}{l}\text { Change in real; } \\
\text { hourly wage btw. } t_{0} \\
\text { and } t_{1}\end{array}$}} \\
\hline & 1.3254 & 1.1033 & 0.4551 & 0.4962 & 0.5981 & 0.3079 & 0.2640 & 0.2395 \\
\hline std. dev. & (4.4804) & (4.6101) & (1.9834) & (3.8376) & (4.6356) & (3.3619) & $(2.5701)$ & $(2.6635)$ \\
\hline$N$ & 273 & 4,898 & 217 & 4,460 & 267 & 4,365 & 253 & 3,985 \\
\hline
\end{tabular}



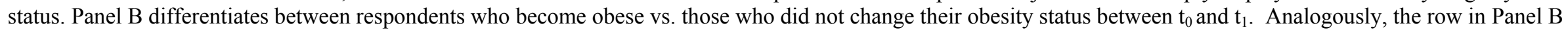
indicate the change in hourly real wages between $\mathrm{t}_{0}$ and $\mathrm{t}_{1}$.

\section{pgijasgo}


Table 3: Relationship Between Wages, Occupational Risk, and Obesity

\begin{tabular}{|c|c|c|c|c|c|c|}
\hline \multirow[b]{2}{*}{ Covariates } & \multicolumn{3}{|c|}{ OLS } & \multicolumn{3}{|c|}{$\mathrm{FE}$} \\
\hline & $\begin{array}{c}\text { lnwage } \\
\text { (1) }\end{array}$ & $\begin{array}{c}\text { lnwage } \\
(2)\end{array}$ & $\begin{array}{c}\text { lnwage } \\
\text { (3) }\end{array}$ & $\begin{array}{c}\text { lnwage } \\
\text { (4) }\end{array}$ & $\begin{array}{c}\text { lnwage } \\
(5)\end{array}$ & $\begin{array}{c}\text { lnwage } \\
(6)\end{array}$ \\
\hline Nonfatalrisk ${ }^{*}$ obese & $\begin{array}{c}0.0118 \\
(0.0073)\end{array}$ & $\begin{array}{c}0.0089 * * * \\
(0.0028)\end{array}$ & $\begin{array}{c}0.0074 * * * \\
(0.0025)\end{array}$ & $\begin{array}{c}-0.0041 * * \\
(0.0019)\end{array}$ & $\begin{array}{c}-0.0046^{* * *} \\
(0.0017)\end{array}$ & $\begin{array}{c}-0.0042 * * \\
(0.0017)\end{array}$ \\
\hline Nonfatalrisk & $\begin{array}{c}-0.0355^{* * *} \\
(0.0039)\end{array}$ & $\begin{array}{l}-0.0003 \\
(0.0019)\end{array}$ & $\begin{array}{l}-0.0023 \\
(0.0018)\end{array}$ & $\begin{array}{c}0.0022 * * \\
(0.0010)\end{array}$ & $\begin{array}{c}0.0060 * * * \\
(0.0015)\end{array}$ & $\begin{array}{c}0.0056 * * * \\
(0.0015)\end{array}$ \\
\hline Obese & $\begin{array}{c}-0.1405 * * * \\
(0.0235)\end{array}$ & $\begin{array}{c}-0.0739 * * * \\
(0.0145)\end{array}$ & $\begin{array}{c}-0.0395 * * * \\
(0.0129)\end{array}$ & $\begin{array}{c}0.0023 \\
(0.0103)\end{array}$ & $\begin{array}{c}0.0005 \\
(0.0099)\end{array}$ & $\begin{array}{l}-0.0015 \\
(0.0098)\end{array}$ \\
\hline Bmi & $\begin{array}{c}0.0313 * * * \\
(0.0059)\end{array}$ & $\begin{array}{c}0.0145 * * * \\
(0.0041)\end{array}$ & $\begin{array}{c}0.0028 \\
(0.0039)\end{array}$ & $\begin{array}{c}0.0099 * * \\
(0.0040)\end{array}$ & $\begin{array}{c}0.0081 * * \\
(0.0038)\end{array}$ & $\begin{array}{c}0.0080 * * \\
(0.0039)\end{array}$ \\
\hline $\mathrm{Bmi}^{\wedge} 2$ & $\begin{array}{c}-0.0005^{* * *} \\
(0.0001)\end{array}$ & $\begin{array}{c}-0.0002 * * * \\
(0.0001)\end{array}$ & $\begin{array}{l}-0.0001 \\
(0.0001)\end{array}$ & $\begin{array}{l}-0.0001 * \\
(0.0001)\end{array}$ & $\begin{array}{l}-0.0001 \\
(0.0001)\end{array}$ & $\begin{array}{l}-0.0001 \\
(0.0001)\end{array}$ \\
\hline $\begin{array}{l}\text { Person-year observations } \\
\text { \# individuals } \\
\text { R-squared }\end{array}$ & $\begin{array}{c}26,019 \\
7,009 \\
0.0499\end{array}$ & $\begin{array}{c}26,019 \\
7,009 \\
0.4103\end{array}$ & $\begin{array}{c}26,019 \\
7,009 \\
0.5203\end{array}$ & $\begin{array}{c}26,019 \\
7,009 \\
0.1144\end{array}$ & $\begin{array}{c}26,019 \\
7,009 \\
0.1867\end{array}$ & $\begin{array}{c}26,019 \\
7,009 \\
0.1934\end{array}$ \\
\hline $\begin{array}{l}\text { Source: NLYS and SOII 19 } \\
\text { an OLS version of equation } \\
\text { estimate Fixed Effects mod } \\
\text { indicates if the BMI exceed } \\
\text { level per } 100 \text { full time empl }\end{array}$ & $\begin{array}{l}1, * * \mathrm{p}<0.05 \\
\mathrm{n} \text { individual } \mathrm{f} \\
\text { de individual } \\
\mathrm{MI} \text { is the con }\end{array}$ & $\begin{array}{l}\text { Robust stand } \\
\text { ects. The three } \\
\text { fects. The thr } \\
\text { BMI measure }\end{array}$ & $\begin{array}{l}\text { rs, clustered a } \\
\text { only differ by } \\
\text { s also only di } \\
\text { talrisk indicat }\end{array}$ & $\begin{array}{l}\text { level, are } \\
\text { variates inc } \\
\text { of covariat } \\
\text { of workplac }\end{array}$ & $\begin{array}{l}\text { eses. The firs } \\
\text { indicated. Th } \\
\text { ed. Obese is a } \\
\text { its at the year }\end{array}$ & $\begin{array}{l}\text { lumns estin } \\
\text { e columns } \\
\text { variable tha } \\
\text { occupation }\end{array}$ \\
\hline
\end{tabular}


Table 4: Robustness Checks and Heterogeneity in Effects

\begin{tabular}{|c|c|c|c|c|c|c|}
\hline \multirow[b]{2}{*}{ Covariates } & \multicolumn{3}{|c|}{ Robustness Checks } & \multicolumn{3}{|c|}{ Effect Heterogeneity } \\
\hline & $\begin{array}{c}\text { no job changers } \\
\text { (1) }\end{array}$ & $\begin{array}{l}\text { lagged dependent } \\
\text { variables } \\
\text { (2) }\end{array}$ & $\begin{array}{c}\text { cluster at } \\
\text { occupational level } \\
\text { (3) }\end{array}$ & $\begin{array}{c}\text { female } \\
(4)\end{array}$ & $\begin{array}{l}\text { age } \\
(5)\end{array}$ & $\begin{array}{c}\text { job physically } \\
\text { demanding } \\
(6)\end{array}$ \\
\hline Nonfatalrisk*obese*[column header] & & & & $\begin{array}{c}0.0016 \\
(0.0040)\end{array}$ & $\begin{array}{l}-0.0007^{*} \\
(0.0004)\end{array}$ & $\begin{array}{l}-0.0039 * \\
(0.0023)\end{array}$ \\
\hline [column header] & & & & $\begin{array}{c}0.0000 \\
(0.0000)\end{array}$ & $\begin{array}{l}-0.0034 \\
(0.0067)\end{array}$ & $\begin{array}{c}0.1686 * * * \\
(0.0259)\end{array}$ \\
\hline Nonfatalrisk*obese & $\begin{array}{c}-0.0046 * * * \\
(0.0018)\end{array}$ & $\begin{array}{l}-0.0026^{*} \\
(0.0014)\end{array}$ & $\begin{array}{c}-0.0042 * * * \\
(0.0016)\end{array}$ & $\begin{array}{c}-0.0044 * * \\
(0.0018)\end{array}$ & $\begin{array}{c}0.0195 \\
(0.0143)\end{array}$ & $\begin{array}{c}0.0038 \\
(0.0054)\end{array}$ \\
\hline Nonfatalrisk & $\begin{array}{c}0.0053 * * * \\
(0.0016)\end{array}$ & $\begin{array}{c}0.0014 \\
(0.0010)\end{array}$ & $\begin{array}{c}0.0056^{* * *} \\
(0.0015)\end{array}$ & $\begin{array}{c}0.0057 * * * \\
(0.0015)\end{array}$ & $\begin{array}{c}0.0058 * * * \\
(0.0015)\end{array}$ & $\begin{array}{c}0.0081 * * * \\
(0.0023)\end{array}$ \\
\hline Obese & $\begin{array}{l}-0.0004 \\
(0.0105)\end{array}$ & $\begin{array}{l}0.0381 * * \\
(0.0169)\end{array}$ & $\begin{array}{l}-0.0015 \\
(0.0098)\end{array}$ & $\begin{array}{c}-0.0020 \\
-0.0044 * *\end{array}$ & $\begin{array}{c}0.0020 \\
(0.0098)\end{array}$ & $\begin{array}{l}-0.0036 \\
(0.0105)\end{array}$ \\
\hline Year FE & $\mathrm{X}$ & $\mathrm{X}$ & $X$ & $X$ & $X$ & $\mathrm{X}$ \\
\hline Occupation FE & $\mathrm{X}$ & $\mathrm{X}$ & $\mathrm{X}$ & $\mathrm{X}$ & $\mathrm{X}$ & $\mathrm{X}$ \\
\hline Industry FE & $\mathrm{X}$ & $\mathrm{X}$ & $\mathrm{X}$ & $\mathrm{X}$ & $\mathrm{X}$ & $\mathrm{X}$ \\
\hline Socio-economic covariates & $\mathrm{X}$ & $\mathrm{X}$ & $\mathrm{X}$ & $\mathrm{X}$ & $\mathrm{X}$ & $\mathrm{X}$ \\
\hline Individual FE & $\mathrm{X}$ & $\mathrm{X}$ & $\mathrm{X}$ & $\mathrm{X}$ & $\mathrm{X}$ & $\mathrm{X}$ \\
\hline Person-year observations & 19,685 & 6,883 & 26,019 & 26,019 & 26,019 & 25,140 \\
\hline \# individuals & 6,217 & 4,206 & 7,009 & 7,009 & 7,009 & 6,862 \\
\hline R-squared & 0.1968 & 0.2110 & 0.1867 & 0.1934 & 0.1867 & 0.1861 \\
\hline
\end{tabular}

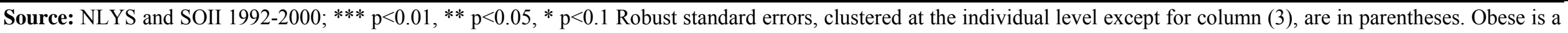

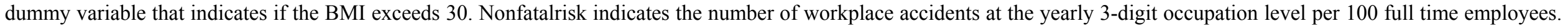

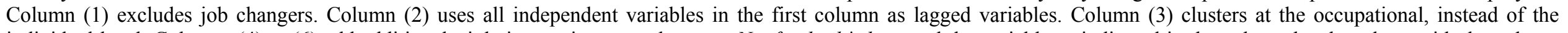

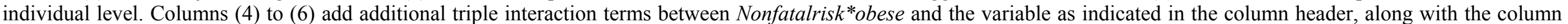

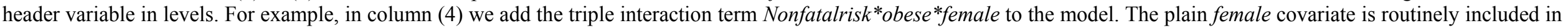

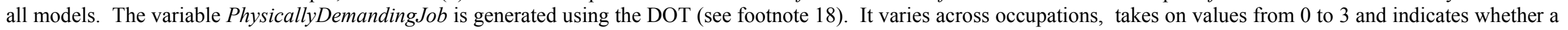
job requires (i) climbing, (ii) reaching, or (iii) stooping, kneeling, crouching or crawling. 


\section{Appendix A: Summary Statistics}

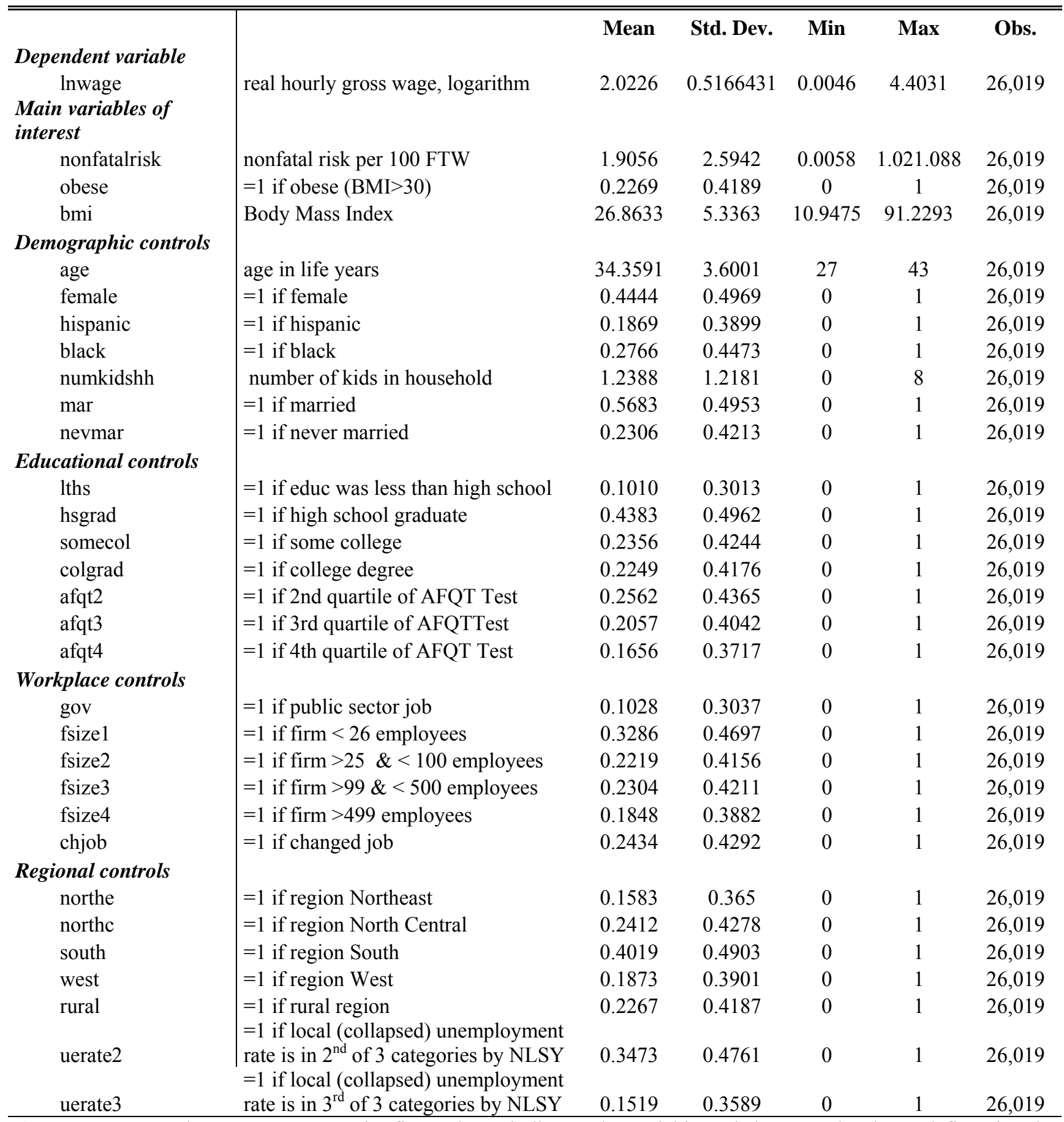

Source: NLYS and SOII 1992-2000; the first column indicates the variable and the second column defines it. The following columns display the mean, the standard deviation, the minimum and maximum variable values, and the number of observations, respectively. 


\section{Appendix B: A Model of Worker Investment in Safety}

\section{The Maximization Problem of the Worker}

In our model of workers' investments in safety (Section 3), worker expected utility is given by

(A1) $E U=[1-p(S, e, p)] U(W-q e)+p(S, e, p) U(W-l-q e)$

The basic worker problem is to choose investments in safety, $e$, to maximize expected utility $E U$

$$
E U^{*} \equiv \max _{e} E U=[1-p(S, e, p)] U(W-q e)+p(S, e, p) U(W-l-q e)
$$

The first-order conditions to this problem are given by

$$
-\frac{\partial p(e)}{\partial e}\left(U_{1}-U_{0}\right)=q\left[(1-p) U_{1}{ }^{\prime}+p U_{0}{ }^{\prime}\right]
$$

If the quantity of worker investments demanded by the firm exceeds the optimal level of investment that the worker would choose, the employer can induce further investments by compensating workers with higher wages. For example, a fully insured worker would not invest, but the employer may find additional investment profitable. Thus, the question becomes what wage increase is necessary to induce the worker to invest beyond the quantities implied by equation (A3)? This wage change can be obtained by differentiating the expected utility function with respect to wages and worker investments to obtain

(A4) $\frac{d W}{d e}=\frac{\frac{\partial p}{\partial e}\left(U_{1}-U_{0}\right)+q\left[(1-p) U_{1}^{\prime}+p U_{0}^{\prime}\right]}{(1-p) U_{1}^{\prime}+p U_{0}^{\prime}} \geq 0$

Equation (A4) indicates the magnitude of the wage change required to keep worker utility constant for a given change in worker investment in safety. If the employer demands the same quantity of worker investments as the worker would choose on his own, equation (A3) implies no change in the 
wage since this would make the numerator in equation (A4) equal to zero. To obtain further investments, equation (A4) shows the magnitude of the wage premium, which is positive because it follows from equation (A3) that $q\left[(1-p) U_{1}{ }^{\prime}+p U_{0}{ }^{\prime}\right]$ exceeds $\frac{\partial p}{\partial e}\left(U_{1}-U_{0}\right)$. The employer would have to pay to obtain additional investment.

If the worker was fully insured, $U_{1}=U_{0}$, he would have no personal incentive to invest: the first term on the right-hand-side of equation (A4) would be zero and the wage increase "charged" by the worker to invest would be given by $d W / d e=q$. This shows that for fully insured workers, the wage increase required to invest in safety would equal the cost of investment $q$. This captures the idea that workers must be compensated for investing beyond their own optimal investment.

\section{The Maximization Problem of the Firm}

The employer's problem is to choose labor $(L)$, investments in safety $(S)$, and worker investments in safety $(e)$ to maximize profits subject to a constraint that workers' utility is equal to $E U^{*}$ (the alternative):

$$
\max _{L, S, e} \pi=m Q(L)-W L-p(S, e, p) A L-c S L
$$

s.t. $\left\{\left[E U^{*}=(1-p(S, e, p)) U_{1}(W-q e)+p(S, e, p) U_{0}(W-q e-l)\right] L\right\}$

The first-order conditions to this problem are given by:

$$
m \frac{\partial Q(L)}{\partial L}=W+p(S, e, p) A+c S
$$

(A7) $-\frac{\partial p}{\partial S} A-\chi \frac{\partial p}{\partial S}\left(U_{1}-U_{0}\right)=c$

$$
\frac{\partial p}{\partial e} A+\chi\left\{\frac{\partial p}{\partial e}\left(U_{1}-U_{0}\right)=-q\left[(1-p) U_{1}^{\prime}+p U_{0}^{\prime}\right]\right.
$$


Equation (A7) yields the optimal level of employer investments in safety $(S)$. The left-handside of the equation is the marginal benefit of investment, which is the sum of the reduction in accident costs and the increase in worker utility resulting from the risk reduction weighted by the value of changing utility by $\$ 1(\chi)$. The increase in utility resulting from the investment is a benefit to the employer because workers accept lower wages in return.

Equation (A8) yields the optimal level of worker investments in safety $(e)$. The left-handside is the marginal benefit of such investment, which consists of the decrease in accident costs plus the increase in weighted utility stemming from the reduced injury risk. The right-hand-side is the investment's marginal cost, which is the worker's cost of investment (q) weighted by his marginal utility of income.

Equation (A6) states that the value of the marginal product of labor must equal its marginal cost, which is the sum of the wage, expected accident cost and cost of firm investment in safety. Solving for the wage $(W)$ yields:

(A9) $W=m \frac{\partial Q(L)}{\partial L}-p(S, e, p) A-c S$,

which shows that wages depend on the level of employer and employee investments in safety through their effects on risk, $p$. Such investments in turn depend on a variety of factors. Equation (A7) shows that optimal employer investments in safety will differ depending on their price $(c)$, productivity $\left(\frac{\partial p}{\partial S}\right)$, accident costs $(A)$, and employees' tradeoff between wages and employer-determined risk. Equation (A8) yields the optimal level of employee investments in safety $(S)$; they depend on their price $(q)$, productivity $\left(\frac{\partial p}{\partial e}\right)$, accident costs $(A)$, and the tradeoff between wages and employee-controlled risk. 
Recall the firm will induce worker investments in safety by paying a higher wage. The wage increase required to keep worker utility constant when the worker invests in safety was given by equation (A4). Multiplying both sides of that equation by the marginal utility of income $\left[(1-p) U_{1}^{\prime}+p U_{0}^{\prime}\right]$ yields

(A10) $\frac{d W}{d e}\left[(1-p) U_{1}^{\prime}+p U_{0}^{\prime}\right]=\frac{\partial p}{\partial e}\left(U_{1}-U_{0}\right)+q\left[(1-p) U_{1}^{\prime}+p U_{0}^{\prime}\right]$

Substituting equation (A10) into equation (A8) gives another version of the first-order conditions for worker investment in safety:

(A11) $-\frac{\partial p}{\partial e} A=\frac{d W}{d e}\left[(1-p) U_{1}{ }^{\prime}+p U_{0}{ }^{\prime}\right] \chi$

The right-hand-side of equation (A11) represents marginal benefits and the right-hand side marginal costs of worker investment in safety. 